\title{
Drug reprofiling and repurposing: a state-of- the-art public-private collaboration model
}

\author{
Hiroshi NAGABUKURO ${ }^{1,2 *}$ and Naoto UEMURA ${ }^{2}$ \\ ARTham Therapeutics Inc., 24-8 Yamashita-cho, Naka-ku, Yokohama, Kanagawa 231-0023, Japan \\ 2 Department of Clinical Pharmacology and Therapeutics, Faculty of Medicine 1-1 Idaigaoka, Hasama-machi, Yufu-shi, Oita 879-5593, Japan
}

\begin{abstract}
Drug repurposing is being actively pursued as a cost- and time-efficient drug discovery and development strategy. We proposed a new public-private partnership model for drug repurposing that involves academic institutions, government, investors, pharmaceutical and biotech companies. The model initially identifies promising hypothesis based on information of pharma assets on shelves, and proves the hypothesis in early clinical settings through academic and industry collaborations. We are currently developing multiple clinical assets including ART001, a novel PI3K $\alpha$ inhibitor for complex vascular malformations, based on this strategy to prove the model as a highly productive drug discovery and drug development framework.
\end{abstract}

Key words: drug repurposing, academia-industry collaboration, vascular malformation

\section{Introduction}

Drug repurposing, so called drug repositioning is one of the promising strategies to identify and deliver a novel therapeutic option to patients. Since conventional drug discovery, and development are time-consuming and costly processes, drug repurposing has been actively explored in both the industry and academic settings through different approaches that include computational/in silico and experimental strategies [1, 2]. Significant benefits from drug repurposing include access to historical safety, pharmacokinetics and pharmacodynamics data in human, and also to accumulated disease biology data.

In addition to individual efforts made by academic institutions and pharmaceutical companies, these publicprivate collaborative initiatives widely call proposals of new utility for discontinued compounds from pharmaceutical companies: MRC-AstraZeneca compound collaboration in UK [3] and Discovering New Therapeutic Uses for Existing Molecules program, which is led by the National Center for Advancing Translational Sciences of National Institutes of Health in the US [4]. Out of these initiatives, multiple compounds have been under clinical development for indications different from the ones original targeted [1].

Provided that safety, pharmacokinetics (PK) and in some cases, pharmacodynamics (PD) are discerned for compounds, they are ready to be repurposed, although the foremost developmental risk is unidentified efficacy for a new indication. Therefore, compelling association between a disease and molecular target and related pharmacology is the essential success factor in addition to marketability

*Correspondence to: Nagabukuro, H.:

hiroshi.nagabukuro@arthamther.com

Received: May 1, 2020; Accepted: May 28, 2020 and feasibility of clinical development. In this mini-review, we introduce our drug repurposing approaches by gaining confidence from reprofiling pharmaceutical assets via a new public-private collaboration.

\section{New Public-Private Partnership for Drug Repurposing}

Since pharmaceutical companies have their focused therapeutic areas and modalities, and drug repurposing opportunities may not necessarily fit their business focus, many of such opportunities are not pursued within originator pharmaceutical companies simply due to these reasons. From a 3-year survey between 2013 to 2015, it turned out that $15 \%$ of Phase 2 and Phase 3 clinical trials were discontinued for companies' strategic reasons [5]. Many of those discontinued assets would not be developed again and "shelved". The academia and industry collaborations mentioned above are recognized as solutions to re-activate clinical development for repurposed indications.

The other solution is to spinout pharma assets and to establish biotech companies that further develop those assets. This approach has been attempted in multiple geographical locations. One good example is IMR-687, a PDE9 inhibitor, which is currently being developed for sickle cell disease by Imara in the US [6]. This molecule originates from a Lundbeck's research and development program for the treatment of neurodegenerative diseases. However, potential utility of a PDE9 inhibitor for sickle cell disease was strongly suggested by academic research [7]. As sickle cell disease was not in Lundbeck's focused areas, they licensed out their PDE9 inhibitors to Cydan (Cambridge, MA, USA) and Cydan created a biotech company called Imara (Boston, MA, USA) along with multiple investors. There are similar 
examples in EU and Japan that include Calypso Biotech (Geneva, Switzerland) (Merck-Serono spinout), Cerevance (Cambridge, UK) (Takeda spinout), AlphaNavi Pharma (Kyoto, Japan) (Sumitomo Dainippon Pharma spinout).

Our approach is based on tight partnership not only between academic institutions and industry, but also with government and investors (Fig. 1). The framework of academia-industry collaboration mainly functions for generating new hypothesis, which is essentially "compound A has therapeutic effects for disease $X^{\prime \prime}$ and its confirmation in both preclinical and clinical settings. The important step here is how we identify hypothesis with high probability of success both clinically and financially so that we invite investors to participate in the repurposing drug development. We also proactively seek governmental grant opportunities (e.g. Japan Agency of Medical Research and Development (AMED)). Accordingly, our efforts spent for hypothesis generation have been significant, successfully invited both venture capitals to participate and accessed AMED grants.

Being therapeutic area-/disease-agnostic is another important aspect of our drug repurposing. In many cases, we did not possesse expertise in the diseases that we targeted. In such cases, we actively sought disease experts who specialize diagnosis, treatments and sometimes clinical trials for a particular indication, and engage them. We occasionally access to patient advocacy groups especially when the disease is an orphan indication to better understand the disease itself as well as patients and their family affected by the disease.

\section{Repurposing Asset Selection}

Many pharmaceutical companies have their own criteria for project selection and decision making at stage gates. For example, AstraZeneca has their five dimensional framework called 5 " $\mathrm{R}$ "s, the most important technical determinants of project success and pipeline quality: right target, right tissue, right safety, right patients, right commercial potential [8].

We are currently pursuing clinical development of multiple assets chosen based on the following criteria: (i) Rationale (pathophysiology), (ii) Mechanism (target modulation), (iii) Safety (toxicology/tolerability) and (iv) Differentiation (competitive advantage). There are two major data categories to measure confidence levels when selecting assets: quality of target validation and quality of asset (Fig. 2). Quality of target validation is measured by successful demonstration with real data from clinical studies, genetics and disease biology. The examples of data sets that are taken into consideration are:

1) Clinical data

- Efficacy, safety, tolerability and pharmacokinetics data

- Early surrogate biomarkers that predict therapeutic effects

- Post-marketing data

- Clinical pharmacology data

2) Genetic data

- Strong causal association between a disease and single nucleotide polymorphisms

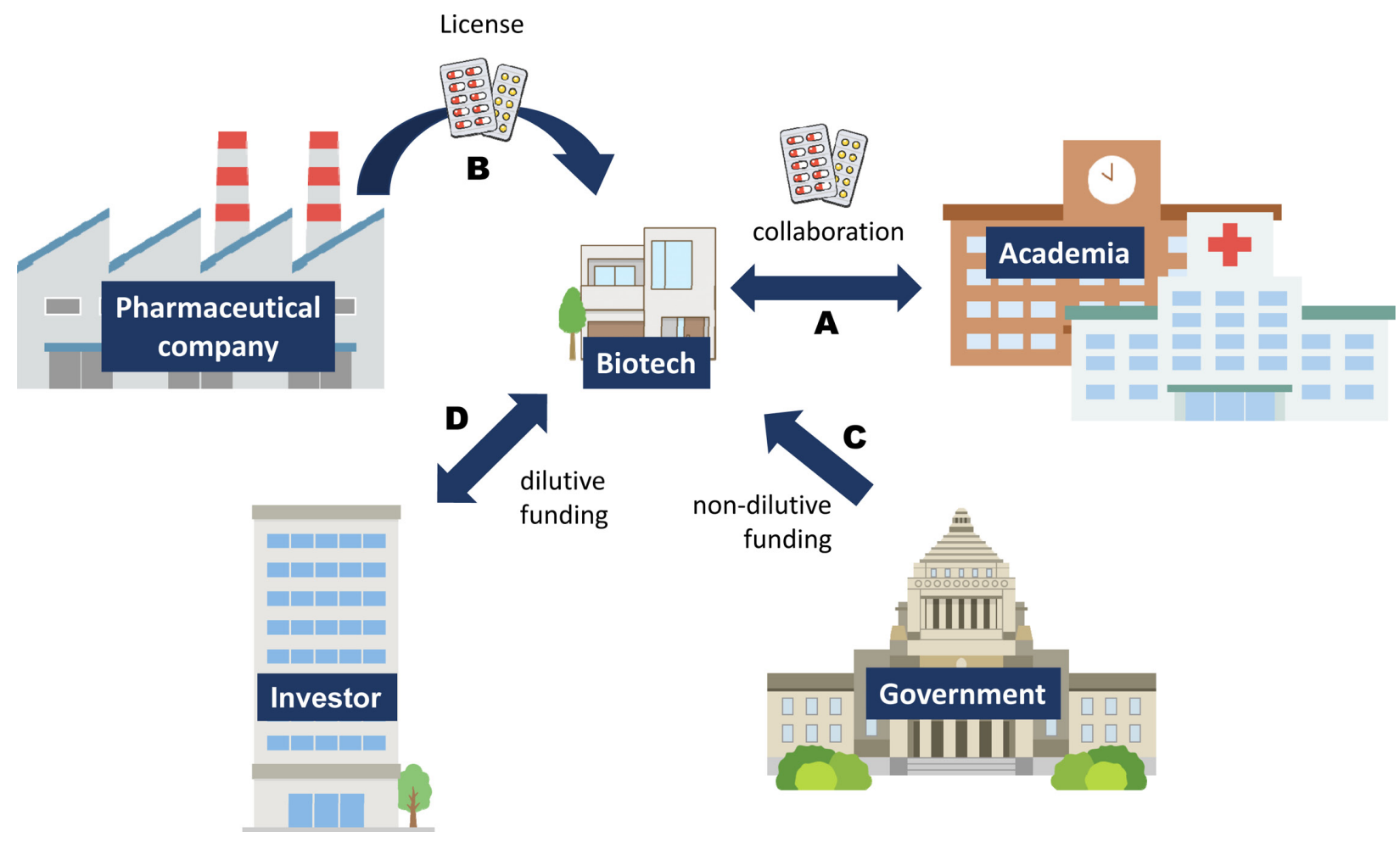

Fig. 1. Public-private collaboration model for drug repurposing. The collaboration between academia and biotech company functions for generating new hypothesis of drug repurposing and its confirmation in both preclinical and clinical settings (A). Clinical candidates on shelves are licensed out to the biotech (B). Research and Development of the biotech is financially supported by both governmental organizations (C) and investors (D). 
- Symptoms caused by genetic mutations that can be pharmacologically modified

3) Disease biology data

- Well-understood etiology and tight connection with target mechanisms

- Disease biology that can be pharmacologically modified

We carefully analyze the data and identify indication(s) for existing candidate compounds/drugs that are rational and highly predictive. In some cases, additional preclinical studies are conducted for critical decision making. This systematic approach will enable the new indication hypothesis for a clinical asset not only for beneficial treatment outcomes in particular pathophysiological conditions, but also for efficient clinical validation through innovative clinical trials.

To assess quality of assets, if they are small molecule compounds, optimal candidate profile comprises of: (i) chemical matter with optimal drugability, (ii) desired pharmacological profile, e.g., potency and selectivity against target molecule; PK-PD relationship, etc., and (iii) safety profile that enables acceptable therapeutic index. The metrics efficiently triages potential assets for our therapeutic area agnostic approach.

\section{ART-001 for Complex Vascular Malformations}

ART-001 (TAK-117) is a selective PI3K $\alpha$ inhibitor, which was originally developed for advanced solid tumors [9]. The PI3K pathway plays critical roles in cell functions (cell growth, proliferation, survival, motility, and metabolism), and is one of the most frequently dysregulated pathways in human cancer [10]. In particular, gain-of-function (GOF) mutations (e.g. E542K, E545K, and H1047R) in the PIK3CA gene, encoding the $\mathrm{p} 110 \alpha$ catalytic subunit of PI3K $\alpha$ have been identified as a major mechanism of increased PI3K signaling that is required for tumor cell proliferation, survival, and metabolism. The PIK3CA mutations have been
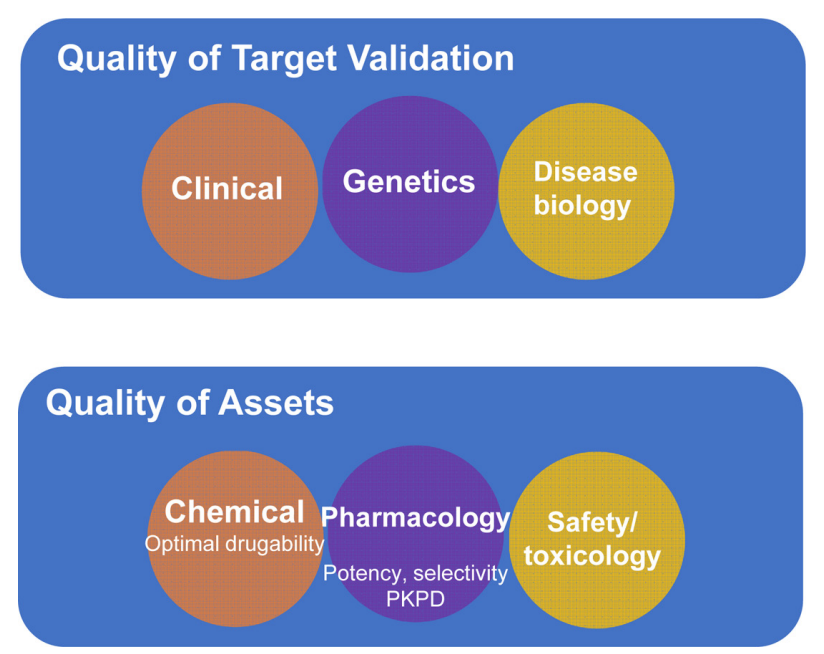

Fig. 2. Key metrics for asset selection for drug repurposing: 1) quality of target validation; 2 ) quality of assets. The metrics efficiently triages potential assets for our therapeutic area agnostic approach. reported to occur in approximately $5 \%$ to $25 \%$ of various solid tumors [11]. ART-001 equipotently inhibits somatic GOF missense mutations in the PIK3CA.

In addition to cancer, there is growing evidence that similar GOF mutations in PIK3CA cause noncancerous overgrowth syndromes [12]. Overgrowth syndromes are characterized by global or localized disproportionate growth associated with other anomalies, including vascular malformations and neurological and/or visceral disorders. Recently, mosaic GOF mutations in PIK3CA or genes coding kinases functioning upstream or downstream of $\mathrm{PI} 3 \mathrm{~K} \alpha$ were identified in greater than $70 \%$ of patients with complex vascular malformations such as venous malformation, Klippel-Trenaunay Syndrome, lymphatic malformation [13-15]. As our development plan is to conduct clinical trials in Japan, we have confirmed that frequency of mosaic PI3K mutation is almost identical to what was reported from EU and US via a collaboration with Oita University Pediatric Department [16]. Moreover, BYL719, a selective inhibitor of PI3K $\alpha$, showed efficacy in preclinical models of venous malformations with mutations not only in PIK3CA, but also in TEK, an upstream of PI3K-AKT-mTOR pathway [14]. In several investigator-initiated clinical studies, sirolimus, a mTOR inhibitor improved clinical scores in patients with vascular malformations $[17,18]$. These past acknowledgements strongly suggest that ART-001 can have benefits for vascular malformations and other PIK3CA-related overgrowth syndromes.

Target validation for ART-001 is mainly attributed to (i) strong genetic association between molecular target PI3K $\alpha$ and diseases; (ii) favorable safety and tolerability profiles of ART-001 from phase 1studies; (iii) ART-001 potently suppress angiogenesis, which is a key etiology of vascular malformations (Fig. 3). Out of these attributes, genetic association had a biggest impact for decision making to trigger clinical development. In addition, clear differentiation from sirolimus was another key scientific rationale of ART-001 development since unlike sirolimus, ART-001 by selectively inhibiting $\mathrm{PI} 3 \mathrm{~K} \alpha$, does not suppress immune function and not increase infectious risk.

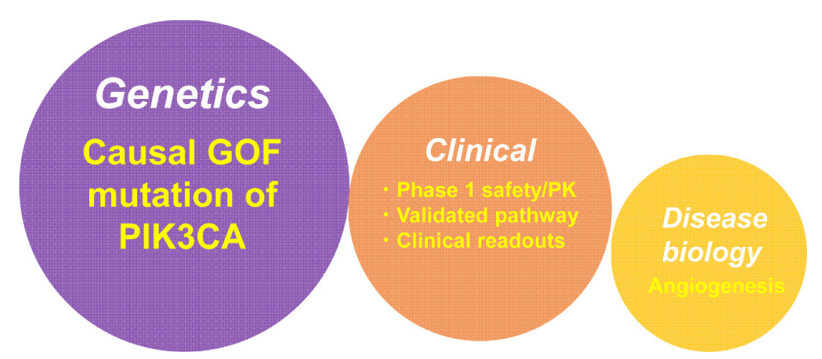

Fig. 3. Key attributes for target validation of ART-001 for vascular malformations: 1) strong genetic association; 2) favorable safety and tolerability profiles of ART-001 in human; 3) angiogenesis as an underling etiology and inhibition by $\mathrm{PI} 3 \mathrm{~K} \alpha$ inhibition. 


\section{Future Perspectives}

We have formulated the flexible framework, which allows drug repurposing using discontinued pharma assets through a new public-private collaboration model, and pursuing clinical development of multiple assets. This new partnership model will make drug development time- and cost-efficient as well as forging significant benefits to patients suffering from diseases with high unmet medical need (e.g. orphan indications), and financial return to both investors as well as originator pharmaceutical companies when a compound is successfully launched.

\section{Acknowledgements}

This work was supported by AMED grants of Innovative Drug Discovery and Development. We thank Drs. Akira Tanaka, Kanako Kuniyeda, Haruhi Ando for careful review of the manuscript. The authors also thank Ms. Mariko Nose for her graphics support.

\section{References}

1. Pushpakom, S., Iorio, F., Eyers, P. A., Escott, K. J., Hopper, S., Wells, A., Doig, A., Guilliams, T., Latimer, J., McNamee, C., Norris, A., Sanseau, P., Cavalla, D. and Pirmohamed, M. 2019. Drug repurposing: progress, challenges and recommendations. Nat. Rev. Drug Discov. 18: 41-58. [Medline] [CrossRef]

2. Park, K. 2019. A review of computational drug repurposing. Transl. Clin. Pharmacol. 27: 59-63. [Medline] [CrossRef]

3. Alzheimers-cancer-and-rare-disease-research-tobenefit-from-landmark-MRC-AstraZeneca-compoundcollaboration-31102012@www.astrazeneca.com [Internet]. https://www.astrazeneca.com/media-centre/pressreleases/2012/Alzheimers-cancer-and-rare-disease-researchto-benefit-from-landmark-MRC-AstraZeneca-compoundcollaboration-31102012.html [accessed May 1, 2020].

4. Discovering New Therapeutic Uses for Existing Molecules. https://ncats.nih.gov/ntu [accessed May 1, 2020].

5. Harrison, R. K. 2016. Phase II and phase III failures: 2013-2015. Nat. Rev. Drug Discov. 15: 817-818. [Medline] [CrossRef]

6. McArthur, J. G., Svenstrup, N., Chen, C., Fricot, A., Carvalho, C., Nguyen, J., Nguyen, P., Parachikova, A., Abdulla, F., Vercellotti, G. M., Hermine, O., Edwards, D., Ribeil, J. A., Belcher, J. D. and Maciel, T. T. 2020. A novel, highly potent and selective phosphodiesterase-9 inhibitor for the treatment of sickle cell disease. Haematologica 105: 623-631. [Medline] [CrossRef]

7. Almeida, C. B., Scheiermann, C., Jang, J. E., Prophete, C., Costa, F. F., Conran, N. and Frenette, P. S. 2012. Hydroxyurea and a cGMP-amplifying agent have immediate benefits on acute vaso-occlusive events in sickle cell disease mice. Blood 120: 2879-2888. [Medline] [CrossRef]

8. Morgan, P., Brown, D. G., Lennard, S., Anderton, M. J., Barrett, J. C., Eriksson, U., Fidock, M., Hamrén, B., Johnson, A., March, R. E., Matcham, J., Mettetal, J., Nicholls, D. J., Platz, S., Rees, S., Snowden, M. A. and Pangalos, M. N. 2018. Impact of a five-dimensional framework on R\&D productivity at
AstraZeneca. Nat. Rev. Drug Discov. 17: 167-181. [Medline] [CrossRef]

9. Juric, D., de Bono, J. S., LoRusso, P. M., Nemunaitis, J., Heath, E. I., Kwak, E. L., Macarulla Mercadé, T., Geuna, E., Jose de Miguel-Luken, M., Patel, C., Kuida, K., Sankoh, S., Westin, E. H., Zohren, F., Shou, Y. and Tabernero, J. 2017. A first-in-human, Phase I, dose-escalation study of TAK-117, A selective PI3Ka isoform inhibitor, in patients with advanced solid malignancies. Clin. Cancer Res. 23: 5015-5023. [Medline] [CrossRef]

10. Fruman, D. A., Chiu, H., Hopkins, B. D., Bagrodia, S., Cantley, L. C. and Abraham, R. T. 2017. The PI3K pathway in human disease. Cell 170: 605-635. [Medline] [CrossRef]

11. Ligresti, G., Militello, L., Steelman, L.S., Cavallaro, A., Basile, F., Nicoletti, F., Stivala, F., McCubrey, J.A. and Libra, M. 2009. PIK3CA mutations in human solid tumors. Cell Cycle 8 : 1352-1358. [Medline] [CrossRef]

12. Keppler-Noreuil, K. M., Sapp, J. C., Lindhurst, M. J., Parker, V. E. R., Blumhorst, C., Darling, T., Tosi, L. L., Huson, S. M., Whitehouse, R. W., Jakkula, E., Grant, I., Balasubramanian, M., Chandler, K. E., Fraser, J. L., Gucev, Z., Crow, Y. J., Brennan, L. M., Clark, R., Sellars, E. A., Pena, L. D. M., Krishnamurty, V., Shuen, A., Braverman, N., Cunningham, M. L., Sutton, V. R., Tasic, V., Graham, J. M. Jr., Geer, J. Jr., Henderson, A., Semple, R. K. and Biesecker, L. G. 2014. Clinical delineation and natural history of the PIK3CArelated overgrowth spectrum. Am. J. Med. Genet. A. 164A: 1713-1733. [Medline] [CrossRef]

13. Limaye, N., Kangas, J., Mendola, A., Godfraind, C., Schlögel, M. J., Helaers, R., Eklund, L., Boon, L. M. and Vikkula, M. 2015. Somatic activating PIK3CA mutations cause venous malformation. Am. J. Hum. Genet. 97: 914-921. [Medline] [CrossRef]

14. Castel, P., Carmona, F. J., Grego-Bessa, J., Berger, M. F., Viale, A., Anderson, K. V., Bague, S., Scaltriti, M., Antonescu, C. R., Baselga, E. and Baselga, J. 2016. Somatic PIK3CA mutations as a driver of sporadic venous malformations. Sci. Transl. Med. 8: 332ra42. [Medline] [CrossRef]

15. Luks, V. L., Kamitaki, N., Vivero, M. P., Uller, W., Rab, R., Bovée, J. V. M. G., Rialon, K. L., Guevara, C. J., Alomari, A. I., Greene, A. K., Fishman, S. J., Kozakewich, H. P. W., Maclellan, R. A., Mulliken, J. B., Rahbar, R., Spencer, S. A., Trenor, C. C. 3rd., Upton, J., Zurakowski, D., Perkins, J. A., Kirsh, A., Bennett, J. T., Dobyns, W. B., Kurek, K. C., Warman, M. L., McCarroll, S. A. and Murillo, R. 2015. Lymphatic and other vascular malformative/overgrowth disorders are caused by somatic mutations in PIK3CA. J. Pediatr. 166: 1048-54.e1, 5. [Medline] [CrossRef]

16. Suenobu, S. 2018 Identification of genetic mutations using tissues with vascular malformations from Japanese pediatric patients, 14th Annual Meeting Japanese Society Study Vascular Anomalies Abstract.

17. Hammer, J., Seront, E., Duez, S., Dupont, S., Van Damme, A., Schmitz, S., Hoyoux, C., Chopinet, C., Clapuyt, P., Hammer, F., Vikkula, M. and Boon, L. M. 2018. Sirolimus is efficacious in treatment for extensive and/or complex slow-flow vascular malformations: a monocentric prospective phase II study. Orphanet J. Rare Dis. 13: 191. [Medline] [CrossRef]

18. Ozeki, M., Nozawa, A., Yasue, S., Endo, S., Asada, R., Hashimoto, H. and Fukao, T. 2019. The impact of sirolimus therapy on lesion size, clinical symptoms, and quality of life of patients with lymphatic anomalies. Orphanet J. Rare Dis. 14: 141. [Medline] [CrossRef] 